\title{
Mixing Models for Slag Covered, Argon Stirred Ladles
}

\author{
Sujay Pandit PATIL, Davviru SATISH, M. PERANANDHANATHAN and Dipak MAZUMDAR
}

Department of Materials Science and Engineering, Indian Institute of Technology, Kanpur 208016 India. E-mail: dipak@iitk.ac.in

(Received on March 19, 2010; accepted on June 1, 2010)

Ninety-five percent bulk mixing times were determined experimentally in water models $(D=0.30 \mathrm{~m}$ and $D=0.60 \mathrm{~m}$ respectively) of a $140 \mathrm{~T}$ industrial ladle fitted with dual 'plugs' (located diametrically opposite at mid bath radius position) in the presence of an overlying, second phase liquid. Experiments were conducted to investigate the influences of gas flow rate, liquid depth, thickness of the upper phase liquid together with the latter's physical properties on mixing time. Within the range of variables studied, it is observed that besides gas flow rate, liquid depth and vessel radius, thickness of the upper phase liquid has the most significant bearing on mixing times. In contrast, considerably less pronounced effect of density and viscosity on mixing was noted. Dimensional analysis and regression of the experimental data show that $95 \%$ bulk mixing times in slag covered, dual plug fitted ladles can be described, in terms of relevant dimensionless groups, via:

$$
\left(\frac{\tau_{\text {mix }, 95 \%} Q}{R^{3}}\right)=196\left(\frac{Q^{2}}{g R^{5}}\right)^{-0.33}\left(\frac{L}{R}\right)^{-1.0}\left(\frac{\Delta L}{R}\right)^{0.3}\left(\frac{\Delta \rho}{\rho_{L}}\right)^{-0.044}\left(\frac{v_{s}^{2}}{g R^{3}}\right)^{0.016}
$$

in which, $Q$ is the gas flow rate, $L$ is the depth of liquid, $R$ is the vessel radius, $\Delta L$ is the thickness of the overlying liquid, $\rho_{L}$ is the density of the bulk liquid and $v_{S}$ is the kinematic viscosity of the upper or slag phase.

Mixing correlations applicable to slag covered, dual plug fitted ladle and its slag free counterpart were found to bear striking similarity. This, as a possibility, suggests that embodying an additional factor, $\left(\approx 6(\Delta L / L)^{0.3} v_{s}^{0.033}\left(\Delta \rho / \rho_{L}\right)^{-0.044}\right)$ into a mixing correlation applicable to a slag free, gas stirred ladle, a correlation for an equivalent slag covered system can be derived. The hypothesis has been tested against axi-symmetrical gas stirred ladle system and towards this, relevant experimental measurements, mixing correlations etc. reported on such systems were applied. These suggest that $95 \%$ bulk mixing time in slag covered, axisymmetrical ladles can indeed be predicted reasonably well embodying the aforementioned addition factor into an existing correlation applicable to an equivalent slag free system.

KEY WORDS: mixing time; experimental measurements; slag covered gas stirred ladles; correlations.

\section{Introduction}

Mixing phenomena in gas stirred ladle systems have been frequently investigated in aqueous models in which, a centrally placed single porous plug/nozzle is used to stir the contents of the ladle. A great deal of information on this is already available in the literature and summarized by Mazumdar and Guthrie ${ }^{1)}$ in a review. While physical model studies of gas stirred ladles using a single, axi-symmetric/ asymmetric plug/nozzle are abundant, not many investigations on ladles stirred with dual plugs/nozzles have been reported in the literature..$^{2-4)}$ Furthermore, practically all the macroscopic mixing models reported so far were derived for "slag-free" situation in which, the presence of an upper phase liquid was entirely ignored. Despite a few studies on mixing time with a simulated slag, ${ }^{5-8)}$ explicit mixing time correlations applicable to slag covered, gas stirred ladles have not been possible till date.

Transient, three dimensional, multiphase, turbulent flow simulation is a pre-requisite to the numerical prediction of mixing time in industrial scale ladles. Flow calculations are invariably complex, time intensive and entail significant computational efforts. Furthermore, currently available CFD soft wares yet do not provide a physically based and sound framework to carry out modeling of flows in steel processing reactors with a great deal of certainty. In the absence of elaborate computational models, macroscopic models, though simplistic, are useful as these provide a reasonable, alternative basis for process analysis and design of steelmaking systems.

Consequently, the primary objective of the present work has been to experimentally investigate mixing phenomena in aqueous models of slag covered, gas stirred ladles and thereby, develop predictive correlations for estimating mixing times. Towards this, experimental results on $95 \%$ bulk mixing times derived from two different size water model ladles, in which, water is agitated by air, introduced through a pair of nozzles located diametrically opposite at mid bath radius position, are first presented and discussed. Explicit correlation is subsequently derived through dimensional 
analysis and regression. Finally, derivation of appropriate mixing time correlations for slag covered ladles in general is addressed and a procedure with particular reference to axisymmetrical, gas stirred ladle systems elucidated.

\section{Present Work}

\subsection{Background}

Figure 1 provides a schematic of gas injection into a steelmaking ladle. Typically $\mathrm{Ar}$ or $\mathrm{N}_{2}$ is injected through a porous plug, located at the base of the ladle, into a bath of molten steel contained within a slightly outwardly tapered, cylindrical vessel. The injected gas, given its buoyancy, rises to the free surface inducing a turbulent recirculatory flow of liquid. This recirculating flow of liquid is well known for enhancing the rate of chemical and thermal homogenization, as well as accelerating the absorption and flotation of harmful non-metallic inclusions into an overlying slag phase. While relatively low gas flow rates $\left(0.05-0.2 \mathrm{Nm}^{3} / \mathrm{h} /\right.$ tonne $)$ are applied to achieve thermal and/or chemical homogenization, more intense stirring conditions are practiced in strong stir ladle stations, if slagmetal reactions are being promoted. Consequently, depending on the specific objective of a gas stirring operation, a wide variety of gas flow rates $\left(0.05\right.$ to $\left.1 \mathrm{Nm}^{3} / \mathrm{h} / \mathrm{t}\right)$ may be applied. This is shown in Table 1, ${ }^{9)}$ in which, gas flow rates for various ladle metallurgy operations are summarized for two different steel mills.

Markedly different slag-metal flow regimes are to be expected in industrial gas stirred ladle systems, depending on argon flow rates and slag layer thickness. While the charac-

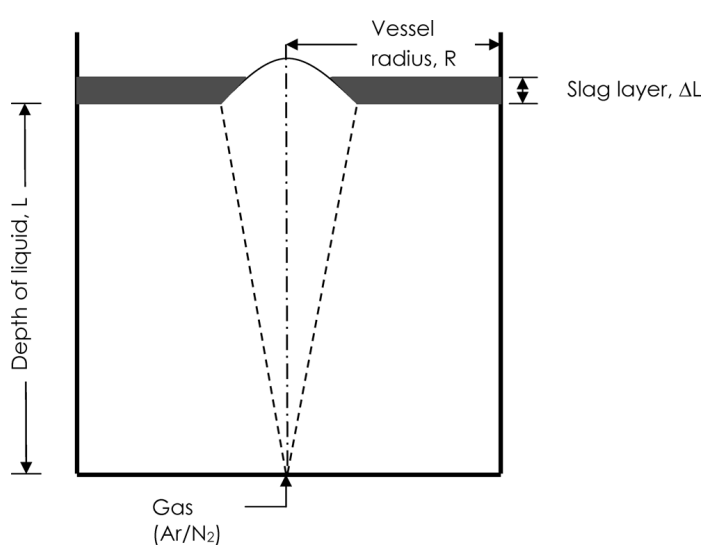

Fig. 1. A schematic of a slag covered, argon stirred ladle.

Table 1. Characteristics of ladle metallurgy steelmaking operations at two different steel plants.

\begin{tabular}{|c|c|c|c|c|c|}
\hline Steelmaker & $\begin{array}{c}\text { Ladle } \\
\text { capacity, } \\
\text { Tonne }\end{array}$ & Ladle treatments & $\begin{array}{l}\text { Operating } \\
\text { flow rate, } \\
\mathrm{Nm}^{3} / \mathrm{hr} \\
\end{array}$ & $\begin{array}{l}\text { Actual gas } \\
\text { flow rate, } \\
\text { m }^{3} / \mathrm{sx}^{-4} 0^{-4}\end{array}$ & $\begin{array}{l}\text { Specific } \\
\text { energy input } \\
\text { rate, } \mathbf{W} / \mathrm{kg}\end{array}$ \\
\hline \multirow[t]{3}{*}{ Plant A } & \multirow{3}{*}{$\begin{array}{c}\mathbf{4 4} \\
(\mathrm{D}=2010 \\
\mathrm{mm} \text { and } \\
\mathrm{L}=1814 \\
\mathrm{~mm})\end{array}$} & $\begin{array}{c}\text { Rinsing } \\
\text { (Homogenization) }\end{array}$ & $5-8$ & $\begin{array}{c}53.8 \\
\text { to }\end{array}$ & $\begin{array}{l}0.015 \\
\text { to }\end{array}$ \\
\hline & & $\begin{array}{l}\text { Ladle Furnace } \\
\text { and alloying }\end{array}$ & $20-25$ & $\begin{array}{c}21.5 \\
\text { to } \\
26.9\end{array}$ & $\begin{array}{c}0.060 \\
\text { to } \\
0.075\end{array}$ \\
\hline & & Desulphurization & \multicolumn{3}{|c|}{ Not practised } \\
\hline \multirow[t]{3}{*}{ Plant B } & \multirow{3}{*}{$\begin{array}{c}\mathbf{1 8 5} \\
(\mathrm{D}=3580 \\
\mathrm{mm} \text { and } \\
\mathrm{L}=2625 \\
\mathrm{~mm})\end{array}$} & $\begin{array}{c}\text { Rinsing } \\
\text { (Homogenization) }\end{array}$ & 20 & 18.3 & 0.017 \\
\hline & & $\begin{array}{l}\text { Ladle Furnace } \\
\text { and alloying }\end{array}$ & 80 & 73.2 & 0.068 \\
\hline & & Desulphurization & 200 & 18.3 & 0.17 \\
\hline
\end{tabular}

teristics of molten steel-slag systems cannot be exactly replicated in aqueous analogues due to mismatches in various physical properties (viz., see Table 2), ${ }^{10)}$ some useful inferences nevertheless can be drawn from water model studies. To illustrate this better, interactions between the upper and the bulk phases in a water model ladle are shown through a set of photographs in Fig. 2 for two different gas flow rates and thicknesses of the upper phases (i.e., petroleum ether and mustard oil respectively). These indicate markedly different behaviors at different flow rates and upper phase properties. For example, at relatively low gas flow rates $\left(2.5 \mathrm{~L} / \mathrm{min} ; \rho_{s} / \rho_{L}=0.6\right)$ similar to those applied for ladle homogenization operations, the overlying liquid, as seen from Figs. 2(a) and 2(b), remains as a distinct upper phase regardless of its thickness. By contrast, at substantially higher gas flows (i.e., those used for de-sulphurization, etc.) (see Fig. 2(c)), the upper phase liquid can be significantly disrupted and entrained subsurface in the form of

Table 2. Physical properties of various liquids and their numerical values used in the present work.

\begin{tabular}{|c|c|c|c|c|}
\hline \multirow[t]{2}{*}{ Liquid } & \multirow[t]{2}{*}{ Characteristics } & \multicolumn{3}{|c|}{ Physical properties } \\
\hline & & $\begin{array}{c}\text { Density, } \\
\mathbf{k g} / \mathbf{m}^{3}\end{array}$ & $\begin{array}{c}\text { Viscosity, } \\
\text { pa.s }\end{array}$ & $\begin{array}{c}\text { Surface } \\
\text { tension,N/m }\end{array}$ \\
\hline Petroleum Ether & \multirow{4}{*}{ Upper phase } & 640 & 0.00038 & 0.0161 \\
\hline Benzene & & 873.8 & 0.00034 & 0.0288 \\
\hline Mustard oil & & 919 & 0.07 & 0.035 \\
\hline Silicon oil & & 968 & 0.097 & 0.053 \\
\hline \multicolumn{5}{|c|}{$\begin{array}{l}\text { Slag density }=2640 \mathrm{~kg} / \mathrm{m}^{3} ; \text { Density of steel }=7200 \mathrm{~kg} / \mathrm{m}^{3} ; \text { Density ratio }=0.38 ; \text { Viscosity } \\
\text { of slag }=\sim 1 \text { Pa.s } ; \text { Viscosity of steel }=0.001 \mathrm{~kg} /(\mathrm{m} . \mathrm{s}) ; \text { Slag - metal interfacial tension: } 0.07 \\
\mathrm{~N} / \mathrm{m} .\end{array}$} \\
\hline
\end{tabular}

(a)
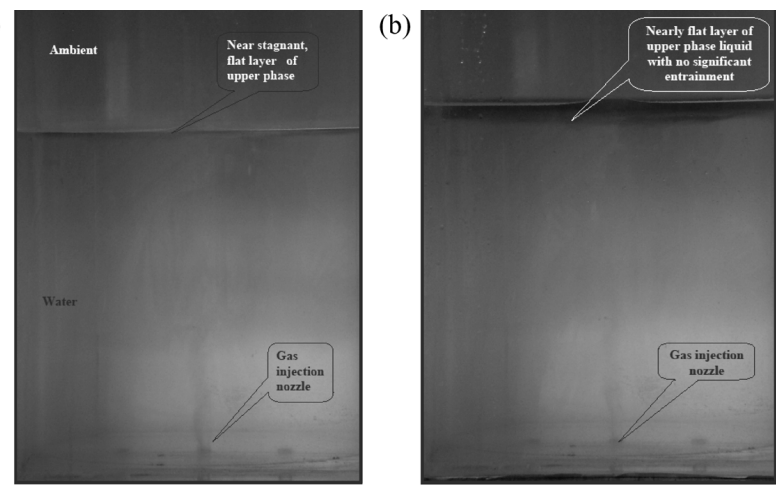

(c)
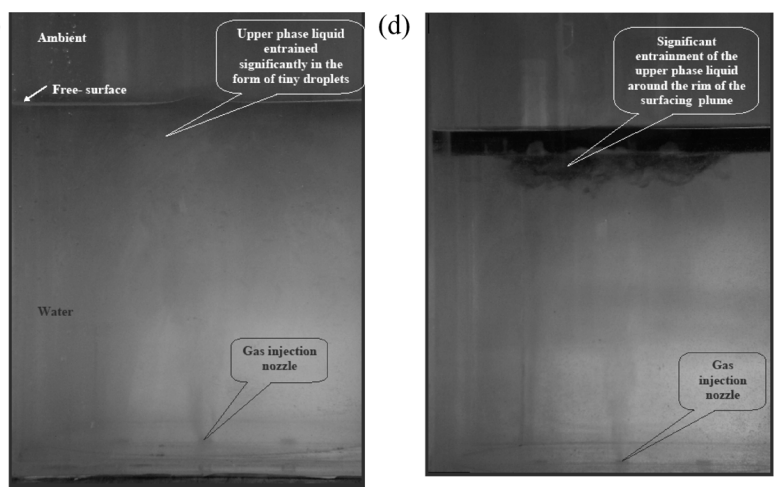

Fig. 2. Behavior of an overlying phase in a gas stirred system ( $R=0.15 \mathrm{~m}$ and $L=0.30 \mathrm{~m}$ ) under different conditions. (a) Petroleum ether (PE) and water system at $6 \times 10^{-3} \mathrm{~W} / \mathrm{kg}$ $\left(\Delta L / L=0.01\right.$ and $\left.\rho_{s} / \rho_{L}=0.6\right)$, (b) PE-water system at $6 \times 10^{-3} \mathrm{~W} / \mathrm{kg} \quad(\Delta L / L=0.06)$, (c) PE-water system at $18 \times 10^{-3} \mathrm{~W} / \mathrm{kg}(\Delta L / L=0.06)$, (d) mustard oil-water system at $6 \times 10^{-3} \mathrm{~W} / \mathrm{kg}\left(\Delta L / L=0.06\right.$ and $\left.\rho_{s} / \rho_{L}=0.92\right)$. 
tiny droplets. With mustard oil as the upper phase, even at the smallest flow rate $(\sim 2.5 \mathrm{~L} / \mathrm{min})$ and a thick ${ }^{* 1}$ layer, extensive deformation of the upper phase is possible around the spout, as is reflected from Fig. 2(d). These figures admittedly paint a somewhat exaggerated picture of the industrial scenario, since actual slag-metal density ratios are only about 0.35 , substantially smaller than those employed here (i.e. 0.6 and 0.9 respectively).

On the basis of the foregoing discussion and illustrations, it is reasonable to assume that at low to moderate specific energy input rates, $\varepsilon_{m} \sim 0.01 \mathrm{~W} / \mathrm{kg}$, the slag layer in an industrial ladle $\left(\rho_{s} / \rho_{L} \sim 0.35\right)$ is likely to remain as a distinct upper phase liquid*2 (i.e. similar to the one shown in Fig. 2(a)), and at much higher specific energy input rates, while a major portion of the slag layer shall still remain intact, some entrainment of the upper phase in the spout region is possible. A scenario such as the one in Fig. 2(c), showing marked entrainment, represents an extreme situation that is unlikely in actual ladle metallurgy steelmaking operations. In the present work, a relatively low specific energy input rate (i.e. $\varepsilon_{m} \sim 0.01 \mathrm{~W} / \mathrm{kg}$ ) and a slag cover $(0.01<\Delta L / L<$ $0.13)$ of relevance to thermal and material homogenization operation in argon stirred ladle $(0.7<L / D<1.5)$, have been considered.

\subsection{Experimental Procedure}

Mixing times were measured in two different cylindrical vessels (I.D. $=0.60 \mathrm{~m}$, and $0.30 \mathrm{~m}$ respectively) in which, water was agitated by injecting air through a pair of nozzles located at the bottom of the vessel at the mid bath radius position. The electrical conductivity measurement technique was applied to monitor mixing and estimate mixing time. The set up comprised of a conductivity probe supplied with a digital conductivity meter $\left(\right.$ Eutech $^{\circledR}$ make, CYBERSCAN 200) which were employed to record changes in the local ion concentration of a pulse tracer $(\mathrm{NaCl}$ or $\mathrm{KCl}$ or $\mathrm{H}_{2} \mathrm{SO}_{4}$ ) added directly to a point on the exposed liquid free surface lying in the proximity of the 'eyes' of the two surfacing plumes. Details of the experimental system, procedure for inferences of $95 \%$ mixing times together with the reliability of measurements have already been reported in a previous publication ${ }^{4)}$ and consequently, not reproduced here. Physical dimensions and the range of operating parameters employed in the study are summarized in Table 3 for ready reference.

\subsection{Quantification of the Influence of the Uupper Phase on Mixing and Plausible Functional Rela- tionships}

The many physical and mathematical model studies ${ }^{11-14)}$ carried to date have combined to confirm that flow phenomena under typical ladle metallurgy steelmaking conditions (viz., $0.7<L / D<1.5, \quad \varepsilon_{m} \sim 0.01 \mathrm{~W} / \mathrm{kg}$ and $v_{L}=10^{-6} \mathrm{~m}^{2} / \mathrm{s}$, negligible overlying second phase etc.) are essentially dominated by the inertial and the gravitational forces. This essentially suggests that viscous forces within the bulk of liq-
Table 3. Physical dimensions of the water model ladles and the operating regimes used in the present study.

\begin{tabular}{|l|l|l|l|l|l|}
\hline $\begin{array}{l}\text { Vessel } \\
\text { No. }\end{array}$ & $\begin{array}{l}\text { Diameter, } \\
\mathbf{m}\end{array}$ & $\begin{array}{l}\text { Liquid } \\
\mathbf{d e p t h}, \mathbf{m}\end{array}$ & $\begin{array}{l}\text { Gas flow rate, } \\
\mathbf{m}^{\mathbf{3}} / \mathbf{s} \mathbf{x} \mathbf{1 0}^{-4}\end{array}$ & $\begin{array}{l}\text { Fractional } \\
\mathbf{s l a g} \mathbf{d e p t h}\end{array}$ & Upper phase liquid \\
\hline I & 0.30 & $0.21-0.30$ & $0.166-0.83$ & $0.01-0.13$ & $\begin{array}{l}\text { Benzene, Petroleum } \\
\text { ether, silicone oil and } \\
\text { Mustard oil }\end{array}$ \\
\hline II & 0.60 & $0.48-0.60$ & 2 to 3.33 & $0.048-0.06$ & $\begin{array}{l}\text { Benzene, Petroleum } \\
\text { ether and Mustard oil }\end{array}$ \\
\hline
\end{tabular}

uid are of only secondary importance as far as the hydrodynamics of the gas stirred ladle system is concerned. What is true for flow must therefore, be naturally true for mixing as well, since the latter can be characterized in terms of the flow velocities and turbulence parameters. Thus, in the absence of any upper phase liquid, mixing time has been expressed as a function of the operating variables according to ${ }^{13)}$ :

$$
\tau_{\text {mix }}=f(L, R, g, Q)
$$

The functional relationship expressed via Eq. (1) is likely to be inadequate for slag covered ladles since liquid flow ${ }^{14)}$ and mixing ${ }^{5-8)}$ are known to be different and somewhat sluggish in the presence of an upper phase liquid. Consequently, one might be tempted here to generalize the above to a slag covered ladle considering additional variables, representing primarily the characteristics of the upper phase, according to:

$$
\tau_{\text {mix }}=F\left(L, R, g, Q, \Delta L, \mu_{s}, \rho_{s}, \sigma_{s-m}, \Delta \rho\right)
$$

To arrive at a realistic equivalent of Eq. (2), it is appropriate to refer here to a recent work $^{10)}$ dealing with the subject of energy dissipation due to slag in gas stirred ladle systems. It is now well known that the upper phase liquid dissipates a part of the input energy ${ }^{14)}$ and in turn, makes flow and mixing somewhat sluggish. The more recent work of Mazumdar and Guthrie ${ }^{10)}$ has shown that under conditions similar to those practiced in ladle homogenization, re-routal of the surfacing plume and the accompanied flow reversal in the spout region due to a relatively thick layer of slag are important phenomena governing energy dissipation in such systems. One might therefore anticipate that thickness of the upper phase liquid $(\Delta L)$ would exert considerable influence on mixing. This is rather well known and has been experimentally confirmed by many independent groups of researchers. ${ }^{5-8)}$ In contrast, physical properties of the upper phase liquid is likely to exert much less influence on bulk flow $^{10,15)}$ and hence, on mixing. These together with our measurements of mixing time in the presence of four different types of upper phase liquids (viz., Table 4) appear to indicate that while interfacial tension is likely to play a less important role (i.e., droplet formation, deformation of the interface etc. are largely absent under the conditions considered here), viscosity and density of the upper phase on the other hand can influence bulk flow and mixing to noticeable extent. This is so as kinematic viscosity of the upper phase governs the extent of motion within the slag

\footnotetext{
*1 Thin and thick slag layer are relative terms. Under ladle metallurgy steelmaking conditions, depending on the size of the ladle and the objective of the refining operations, the volume of slag (and hence its thickness) can vary appreciably. Data collected from several industrial size vessels (44 to $185 \mathrm{t}$ ) indicate slag layer thickness varying between 3 and $7 \%$ of the bath depth. The thickness of the upper phase liquid considered in this study ranges between 1 to $13 \%$ of the bath depth and is therefore, regarded on a relative scale, as a thick slag.

*2 Typically, the top of the slag layer is crusty due to pronounced heat loss while the region underneath is likely to remain molten.
} 
Table 4. Experimentally determined $95 \%$ bulk mixing times for four different types of upper phase liquid as a function of their thickness (net gas flow rate $=$ $0.66 \times 10^{-4} \mathrm{~m}^{3} / \mathrm{s} \quad(=4 \mathrm{~L} / \mathrm{min})$, nozzle position $=$ $\pm 0.5 R$, vessel radius $=0.30 \mathrm{~m}$ and liquid depth $=$ $0.30 \mathrm{~m})$.

\begin{tabular}{|c|c|c|c|c|c|c|c|}
\hline \multirow{2}{*}{ Upper phase liquid } & \multicolumn{3}{|c|}{ Properties } & \multicolumn{5}{c|}{$95 \%$ Mixing Time, $\mathbf{~}$} \\
\cline { 2 - 8 } & $\boldsymbol{\rho}, \mathbf{k g m}^{-3}$ & $\begin{array}{c}\boldsymbol{\sigma}, \\
\text { N/m }\end{array}$ & $\begin{array}{c}\boldsymbol{\mu}, \\
\mathbf{m P a . s}\end{array}$ & \multicolumn{4}{c|}{ Thickness of upper phase, mm } \\
\cline { 5 - 9 } & & & & $\mathbf{1 0}$ & $\mathbf{2 0}$ & $\mathbf{3 0}$ & $\mathbf{4 0}$ \\
\hline Petroleum Ether & 640 & 0.016 & 0.38 & 24 & 28 & 32 & 35 \\
\hline Benzene & 873 & 0.028 & 0.34 & 26 & 29 & 33 & 35 \\
\hline Mustard oil & 919 & 0.035 & 70.0 & 43 & 49 & 53 & 55 \\
\hline Silicone oil & 968 & 0.053 & 97 & 43 & 45 & 48 & 53 \\
\hline
\end{tabular}

layer while density differential/ratio determines the slag eye area and hence the severity of flow reversal in the spout region. ${ }^{10)}$ Both these properties of the upper phase are therefore likely to determine the extent of energy dissipation, influencing bulk mixing time as has been observed experimentally. As a first approximation, it is therefore reasonable to consider mixing time in slag covered ladles to be a function of operating variables and physical properties of the upper phase liquid according to:

$$
\tau_{\text {mix }}=F^{\prime}\left(L, R, g, Q, v_{s}, \Delta L, \frac{\Delta \rho}{\rho_{L}}\right)
$$

Adapting Rayleigh's method of indices, six different dimensionless groups can be derived from Eq. (3). In non dimensional form, Eq. (3) can be represented as:

$$
\left(\frac{\tau_{\text {mix }} Q}{R^{3}}\right)=C_{1}\left(\frac{Q^{2}}{g R^{5}}\right)^{a}\left(\frac{L}{R}\right)^{b}\left(\frac{\Delta L}{R}\right)^{c}\left(\frac{v_{s}^{2}}{g R^{3}}\right)^{d}\left(\frac{\Delta \rho}{\rho_{L}}\right)^{e} \ldots
$$

in which, $C_{1}$, is a dimensionless constant and depends on the definition of mixing, the location of the probe in the system, the gas injection configuration and so on. The values of $C_{1}, a, b, c, d$ etc. in Eq. (4), as summarized in the subsequent section, were determined by carrying out a large number of experiments in two different size water model ladles as a function of $Q, L, \Delta L$ etc. In these, due care was taken to ensure a Froude dominated flow regime and this necessitated that slag layer thickness is not too large. Accordingly, in majority of the experiments, the value of the dimensionless slag layer thickness, $\Delta L / L$, was contained in the range 1 to $13 \%$.

\subsection{Determination of the Pre-exponent and Various Exponents in Eq. (4) for Ladles Fitted with Dual Plugs Located Diametrically Opposite at the Mid Bath Radius Position}

Mixing times were determined in two different vessels for various depths of slag layer as a function of gas flow rate, bulk liquid depth and four different types of upper phase liquid (viz., Table 2). The gas flow rates were so chosen that the specific potential energy input rate to the system (defined as: $\rho_{L} g Q L / \rho_{L} \pi R^{2} L$ ) remained close to $0.01 \mathrm{~W} / \mathrm{kg}$. In Figs. 3(a) and 3(b), the variation of mixing times as a function of gas flow rate is shown under a variety (a)

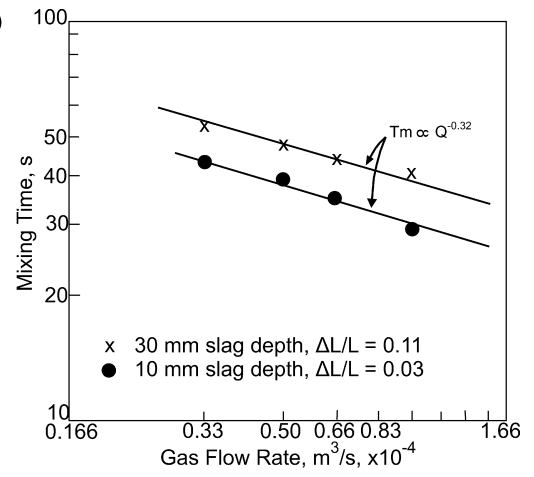

(b)

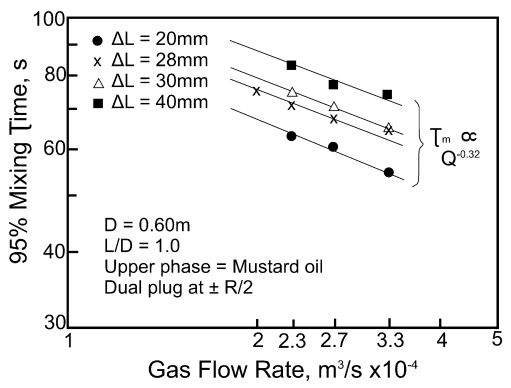

Fig. 3. Experimentally measured $95 \%$ bulk mixing times as a function of gas flow rates for two different size vessels and different thickness of the upper phase liquid. (a) $D=0.60 \mathrm{~m}$ and (b) $D=0.30 \mathrm{~m}$.

of experimental conditions. There, it is readily seen that despite the presence of an upper phase liquid, a relationship of the type $\tau_{m} \infty Q^{-1 / 3}$ is respected reasonably well. Such a dependence of mixing time on gas flow rate, as one would note here, has been reported in the past by many investigators for slag free, axisymmetrical gas stirred systems. ${ }^{1)} \mathrm{A}$ near $1 / 3$ exponent on gas flow rate in Figs. 3(a) and 3(b) is indicative of the fact that within the range of gas flow rates and slag depths considered in this work, hydrodynamics in the bulk of aqueous phase is essentially governed by the inertial and gravitational forces (i.e., Froude dominated). ${ }^{1)}$

Several experiments were also carried out for different depths of the bulk phase liquid maintaining the depth of the upper phase as well as the gas flow rate constant. Results thus obtained are shown in Fig. 4. There, it is readily apparent that experimental data points over a wide range could be correlated reasonably accurately via a functional relationship of the type, $\tau_{\text {mix }} \infty L^{-1.0}$. It is interesting to note that the observed dependence of mixing time on liquid depth is substantially more steep than the one reported earlier for an equivalent slag free system ${ }^{4)}$ i.e., $\tau_{\text {mix }} \infty L^{-0.6}$ (see also later). Similarly, in Figs. 5(a) through 5(c), experimental measurements of mixing times as a function of the depths of the upper phase liquid are shown for a wide range of experimental conditions. These evidently confirm a relationship of the type $\tau_{\text {mix }} \infty \Delta L^{0.3}$ between mixing time and slag layer thickness.

On the basis of the experimental results presented so far, it is therefore reasonable to conclude that the following functional relationships exist between mixing time and the operating parameters namely, $Q, L$ and $\Delta L$ in a slag covered, dual plug fitted ladle viz.,

$$
\begin{gathered}
\tau_{\text {mix }, 95 \%}{ }^{\infty} Q^{-0.33} \\
\tau_{\text {mix }, 95 \%} \infty L^{-1.0}
\end{gathered}
$$




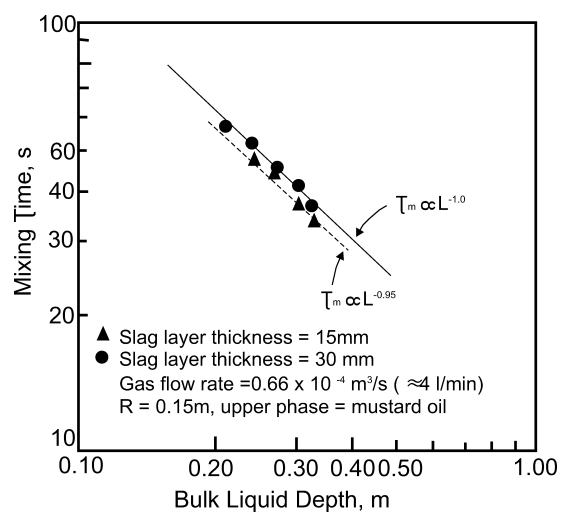

Fig. 4. Experimentally measured $95 \%$ bulk mixing times as a function of the bulk phase liquid depths (upper phase liquid $=$ mustard oil)
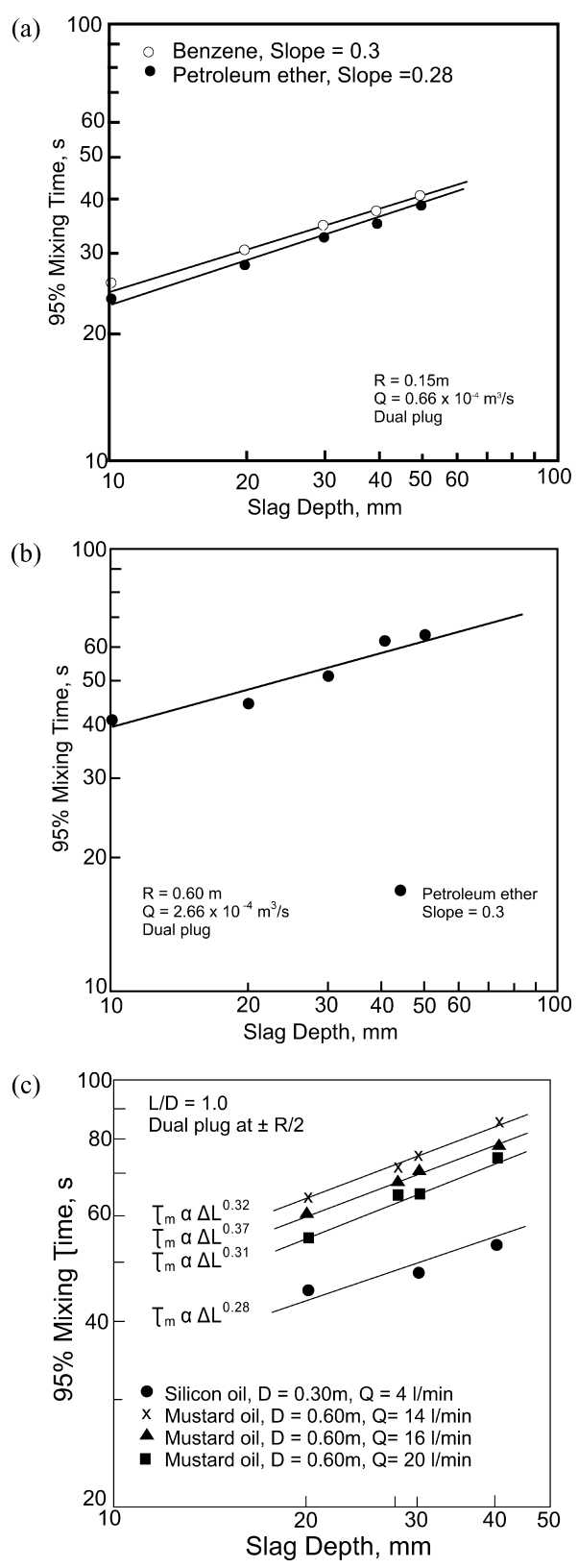

Fig. 5. (a) Experimentally measured $95 \%$ bulk mixing times as a function of the depth of the upper phase liquid. (a) Lighter upper phase liquid in the smaller ladle ( $D=0.30 \mathrm{~m}$ ), (b) lighter upper phase liquid in the bigger ladle $(D=0.60 \mathrm{~m})$, and (c) heavier liquids in both smaller $(D=0.30 \mathrm{~m})$ and bigger $(D=0.60 \mathrm{~m})$ ladles. and

$$
\tau_{\text {mix }, 95 \%} \infty(\Delta L)^{0.3}
$$

Accordingly, Eq. (4) can be represented as:

$$
\left(\frac{\tau_{\text {mix }} Q}{R^{3}}\right)=C_{1}\left(\frac{Q^{2}}{g R^{5}}\right)^{0.33}\left(\frac{L}{R}\right)^{-1.0}\left(\frac{\Delta L}{R}\right)^{0.3}\left(\frac{v_{s}^{2}}{g R^{3}}\right)^{d}\left(\frac{\Delta \rho}{\rho_{L}}\right)^{e}
$$

\subsection{Non Linear Multiple Regression and the Explicit Mixing Time Correlation}

To determine the pre-exponent, $C_{1}$ and the exponents $\mathrm{d}$ and e in Eq. (8) as many as forty experiments were carried out in the two different size water model ladles as a function of gas flow rates, depth of slag layer and bulk liquid depth, employing different types of upper phase liquid. Based on such, a multiple, non linear regression was carried out. ${ }^{16)}$ This provided $C_{1}=196, d=0.016$ and $e=-0.044$ together with a $R^{2}$ value of 0.80 . Given such, the explicit relationship among mixing times, operating variables and physical properties of the upper phase liquid can be stated in dimensionless form via the following equation:

$$
\begin{aligned}
\left(\frac{\tau_{\text {mix }} Q}{R^{3}}\right)= & 196\left(\frac{Q^{2}}{g R^{5}}\right)^{0.33}\left(\frac{L}{R}\right)^{-1.0}\left(\frac{\Delta L}{R}\right)^{0.3}\left(\frac{v_{s}^{2}}{g R^{3}}\right)^{0.016} \\
& \times\left(\frac{\Delta \rho}{\rho_{L}}\right)^{-0.044}
\end{aligned}
$$

In terms of the key variables, the preceding relationship can be re-cast in the following explicit form, viz.,

$$
\tau_{\mathrm{mix}, 95 \%} \approx 90 Q^{-0.33} L^{-1.0} R^{2.0}(\Delta L)^{0.3} v_{s}^{0.033}\left(\frac{\Delta \rho}{\rho_{L}}\right)^{-0.044}
$$

or, in terms of a dimensionless slag depth $\eta,(=\Delta L / L)$, as:

$$
\tau_{\text {mix }, 95 \%} \approx 90 Q^{-0.33} L^{-0.7} R^{2.0} \eta^{0.3} v_{s}^{0.033}\left(\frac{\Delta \rho}{\rho_{L}}\right)^{-0.044}
$$

Equations (10) and (11) provide the desired relationship among mixing time, operating variables and the relevant characteristics of the upper phase liquid for a twin plug fitted ladle. ${ }^{3}$ The effectiveness of regression is illustrated in Fig. 6. Considering uncertainty to the tune of 20 to $25 \%$ in such experimental measurements due to inherent flow transients etc., the fitting of experimental data to Eq. (10) can be considered reasonable. It is important to reiterate here that the preceding relationships have been formulated to cater to lade homogenization and are specific to Froude dominated, slag covered, dual plug fitted ladles subject to the conditions (i) $0.7<L / D<1.5$, (ii) $\varepsilon_{m}=0.01 \mathrm{~W} / \mathrm{kg}$ (max), (iii) $v_{L}=10^{-6} \mathrm{~m}^{2} / \mathrm{s}$ and (iv) $0.01<\eta<0.13$. Their extrapolation to conditions beyond the currently validated range is uncertain.

Mixing times in the presence of different types of upper phase liquid as shown in Table 4 indicate that measured 


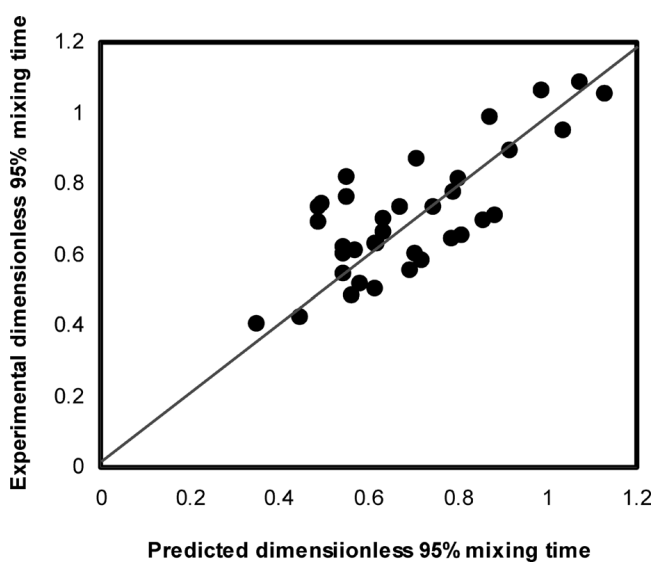

Fig. 6. Effectiveness of regression to illustrate the adequacy of Eq. (11) to dual plug fitted ladles under different operating conditions.

mixing times are practically identical between benzene and petroleum ether despite some differences in their physical properties. In contrast, significantly longer mixing times (by a factor of 1.7 or so) were recorded with mustard /silicone oil as the upper phase liquid under similar operating conditions. Since density and surface tension of mustard oil are not as much different from those of benzene or petroleum ether (see Table 1(a)), it is likely that prolonged mixing times in the case of mustard/silicone oil are the result of latter's remarkably higher viscosity. Given that a five fold higher viscosity extends mixing times by about 60 to $70 \%$, one might anticipate here a rather weak dependence of mixing time on the viscosity of the upper phase liquid. Indeed, results presented in Table 4, in general, appear to indicate only marginal dependence of mixing time on the physical properties of the upper phase liquid. This has been reflected well through the small exponents on kinematic viscosity and density in Eqs. (10) and (11) respectively. It is important to mention here that a large density differential (i.e., a lighter slag) necessitates less energy to push the upper phase liquid for creating the slag eye. In contrast, a more viscous upper phase liquid would tend to dissipate more energy due to viscous work. Looked at from such stand points, counter acting influences of kinematic viscosity and density of the upper phase liquid on bulk mixing time, as reflected from Eq. (11), appear to be physically consistent.

It is instructive to note here that Iguchi and coworkers ${ }^{15)}$ had carried out extensive measurements of various flow properties in similar size water model of an argon stirred ladle as a function of the physical properties of the upper phase liquid. These authors noted that liquid rise velocity (both mean and fluctuating components), bubble rise velocity, bubble frequency, gas hold up etc. do not depend on the nature of the upper phase liquid to any significant extent. This as a distinct possibility suggests that mixing times are expected to be weakly dependant on the physical properties of the upper phase liquid, as has been observed in this study. This is so as mixing is the result of convection and turbulence diffusion phenomena. It is therefore reasonable to conclude that "thickness" rather than physical properties of the upper phase liquid is a dominant characteristic of the upper phase liquid and exerts significant influence on mixing time in slag covered ladles.

\subsection{Mixing Time Correlation Applicable to Axisym- metrical, Slag Covered, Gas Stirred Ladle Systems}

Recently, Mandol and coworkers ${ }^{4)}$ have proposed a mixing time correlation for a slag free gas stirred ladle, fitted with dual porous plug (placed at $\pm R / 2$ ), according to:

$$
\tau_{\text {mix }, 95 \%} \approx 15 Q^{-0.38} L^{-0.56} R^{2.0}
$$

Remarkably, there is striking similarity between Eqs. (11) and (12) as far as exponents on $Q, L$ and $R$ are concerned. Considering experimental uncertainty to the tune of $\pm 20 \%$ or so associated typically with such measurements, one may, as a first approximation consider the dependence of mixing time on $L, R$ and $Q$ as expressed via Eqs. (11) and (12) to be practically equivalent. Given such, one can manipulate Eqs. (11) and (12) and arrive at the following relationship:

$$
\tau_{\text {mix }, 95 \%, \text { slag }} \approx \tau_{\text {mix }, 95 \%, \text { no-slag }}\left[6 \eta^{0.3} v_{s}^{0.033}\left(\frac{\Delta \rho}{\rho_{L}}\right)^{-0.044}\right] \ldots
$$

This as a distinct possibility suggests that embodying the factor, $\left(\approx 6 \eta^{0.3} v_{s}^{0.033}\left(\Delta \rho / \rho_{L}\right)^{-0.044}\right)$, into a mixing time model applicable to slag-free ladles, a correlation for an equivalent slag covered, gas stirred ladle system can be readily deduced. To test this hypothesis further, mixing time in an axisymmetrical gas stirred ladle system has been considered. More than two decades back, Mazumdar and Guthrie $^{17)}$ proposed a semi-empirical correlation, in SI units, for such system as:

$$
\tau_{\text {mix }, 95 \%, \text { Axisym. }} \approx 25.4 Q^{-0.33} L^{-1.0} R^{2.33}
$$

Equation (14), as one would note here, is applicable to Froude dominated ladle flows (i.e., (i) $0.5<L / D<2.0$, (ii) $\varepsilon_{m} \sim 0.01 \mathrm{~W} / \mathrm{kg}$ and (iii) $v_{L}=10^{-6} \mathrm{~m}^{2} / \mathrm{s}$ ) in the absence of any upper phase liquid. Based on the discussion presented above, an appropriate form of Eq. (14), applicable to an equivalent slag covered system, can be represented as :

$$
\tau_{\text {mix }, 95 \%, \text { Axisym.slag }} \approx 25.4 Q^{-0.33} L^{-1.0} R^{2.33} G
$$

Given, $G\left(\approx 6 \eta^{0.3} v_{s}^{0.033}\left(\Delta \rho / \rho_{L}\right)^{-0.044}\right)$, the explicit mixing correlation for axisymmetric, slag covered ladle becomes:

$$
\begin{aligned}
& \tau_{\text {mix, } 95 \%, \text { Axisym.slag }} \\
& \quad \approx 152 Q^{-0.33} L^{-1.0} R^{2.33}\left[\eta^{0.3} v_{s}^{0.033}\left(\frac{\Delta \rho}{\rho_{L}}\right)^{-0.044}\right] \ldots
\end{aligned}
$$

As pointed out already, a few experimental investigations on axisymmetric, gas stirred system in the presence of an upper phase liquid have been carried out and reported in the

\footnotetext{
*3 The empirical correlations derived in this study were obtained from gas stirred systems which were agitated by single hole, straight nozzles. Since gas flow rate employed were small and furthermore since in ladle metallurgy steelmaking, hydrodynamic conditions at the nozzle or orifice are not critical to flow recirculation produced, according we consider that details of gas injection device are inconsequential to the conclusions drawn from this work.
} 
literature. ${ }^{5-8)}$ Not all such measurements can however be applied here to evaluate the adequacy of Eq. (16), since energy input regimes, degree and definition of mixing etc. employed in these studies are beyond the range for which Eq. (16) holds. Extensive comparison could only be attempted against measurements reported by Kim and Frue$\mathrm{han}^{5)}$ as well as some recent experimental results ${ }^{18)}$ obtained in our laboratory. In Fig. 7(a), experimentally measured $95 \%$ mixing times ${ }^{5)}$ are compared directly against equivalent estimates derived from Eq. (16). There, excellent agreement between the two is readily apparent. Similar conclusion readily follows from Fig. 7(b) in which, experimental measurements for two different size, axisymmetric water model ladles have been applied to assess the adequacy and appropriateness of Eq. (16). Evidently, the supposition that a mixing correlation for a slag covered ladle can be derived from the one applicable to an equivalent slag free condition, has been substantiated reasonably well through Figs. 7(a) and 7(b). Looked at from such stand points, the factor, $G\left(\approx 6 \eta^{0.3} v_{s}^{0.033}\left(\Delta \rho / \rho_{L}\right)^{-0.044}\right)$, appears to have some generality. This is being currently evaluated further with reference to an eccentric, single plug fitted gas stirred ladle system.

\subsection{Application to the Modeling of Industrial, Slag Covered, Gas Stirred Ladle System}

Extrapolation of mixing models developed in this work to actual steelmaking ladles is unlikely to be constrained due to the mismatch of physical properties of liquids as long as the flow phenomena within the bulk of liquid is Froude dominated and other conditions such as, $0.70<$

(a)
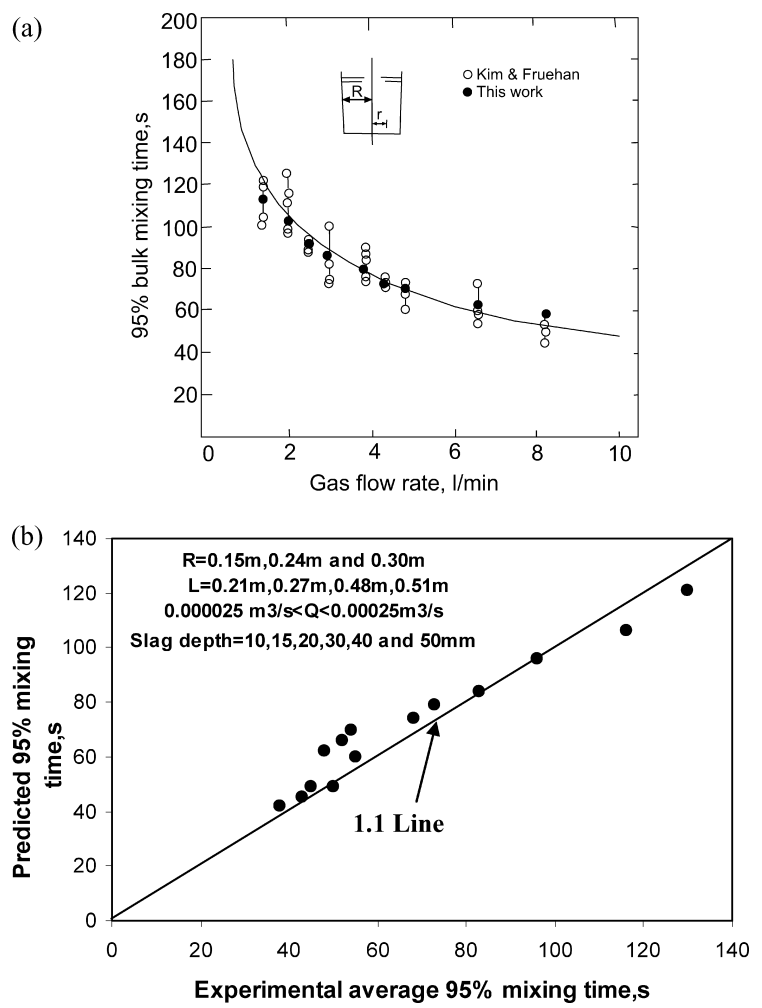

Fig. 7. Effectiveness of Eq. (16) to describe of mixing times in slag covered, axisymmetric gas stirred system. Comparisons of predictions against experimental measurements of (a) Kim and Fruehan ${ }^{5)}$ and (b) Patil. ${ }^{19)}$
$L / D<1.5, \varepsilon_{m} \sim 0.01 \mathrm{~W} / \mathrm{kg}, v_{L}=10^{-6} \mathrm{~m}^{2} / \mathrm{s}$ and $0.01<\eta<0.13$ etc. are respected. Therefore, mixing models derived in this work are likely to constitute a plausible framework for analysis of the efficiency of industrial ladle homogenization operations. Direct measurements nevertheless are desirable to substantiate such assertions. Thus, embodying typical numerical values of viscosity $(=1 \mathrm{~Pa} \cdot \mathrm{s})$ as well as density of slag $\left(2640 \mathrm{~kg} / \mathrm{m}^{3}\right)$ and molten steel $\left(7200 \mathrm{~kg} / \mathrm{m}^{3}\right)$ in Eq. (16), an explicit form of the latter applicable to industrial scale, slag covered, axisymmetrical ladle system can be conveniently derived and represented as:

$$
\tau_{\text {mix }, 95 \%, \text { Axisym.slag }} \approx 120 \eta^{0.3} Q^{-0.33} L^{-1.0} R^{2.33}
$$

In addition, the proposed correlations can provide necessary guide lines for correlating flow rates in model and full scale systems of gas stirred ladle systems, since slag rather than no slag, is more typical of industrial practices. As corresponding time scales in geometrically and dynamically similar systems vary in accordance with $\lambda^{1 / 2}$ (i.e., $=$ $\tau_{\text {mix,mod }} / \tau_{\text {mix,f.s }}$ ), consequently adapting Eq. (16) between model and full scale systems, one can arrive at the following relationship for axisymmetric gas stirred ladle systems, i.e.,

$$
\begin{aligned}
\frac{\tau_{\text {mix } \text { mod }}}{\tau_{\text {mix }, f . s}}= & \lambda^{0.5} \\
= & \left(\frac{Q_{\text {mod }}}{Q_{f . s}}\right)^{-0.33}\left(\frac{L_{\text {mod }}}{L_{f . s}}\right)^{-1.0}\left(\frac{R_{\text {mod }}}{R_{f . s}}\right)^{2.33} \\
& \times\left(\frac{v_{s, \text { mod }}}{v_{s, f . s}}\right)^{0.033}\left(\frac{\left(\Delta \rho / \rho_{L}\right)_{\text {mod }}}{\left(\Delta \rho / \rho_{L}\right)_{f . s}}\right)^{-0.44} .
\end{aligned}
$$

On the basis of the geometrical scale factor, $\lambda$, the preceding relationship is simplified to:

$$
\frac{Q_{\mathrm{mod}}}{Q_{f . s}}=K \lambda^{5 / 2}
$$

in which, $K$ is a numerical constant whose value depends on the choice of the upper phase liquid vis à vis the bulk, in the model study program. For example, if oil is used to represent the upper phase $\left(\rho_{s}=920 \mathrm{~kg} / \mathrm{m}^{3}\right.$ and $\mu_{s}=$ $0.07 \mathrm{~kg} /(\mathrm{m} \cdot \mathrm{s}))$ in an aqueous model, $K=1.038$. This further implies that conventional flow rate scaling relationship ${ }^{1)}$ i.e., $Q_{\text {mod }} / Q_{f . s}=\lambda^{5 / 2}$, for all practical purposes, continues to apply to slag covered gas stirred ladle system.

As a final point, mixing time correlation (viz., Eq. (17)) developed in this work can be applied in conjunction with a fully predictive slag eye area correlation ${ }^{19)}$ i.e.,

$$
\frac{A_{\text {eye }}}{L \Delta L}=3.25\left(\frac{\Delta \rho}{\rho_{L}}\right)^{-0.55}\left(\frac{U_{P}^{2}}{g \Delta L}\right)^{1.28}\left(\frac{v_{s}}{\Delta L U_{P}}\right)^{-0.05} \ldots
$$

to formulate a constrained optimization problem to evolve operating guidelines for melt shop (viz., in terms of optimal argon flow rates, slag layer thickness and so on) ensuring simultaneously adequate mixing and minimal re-oxidation (through the exposed slag eye area). Work in this direction 
is currently in progress in our laboratory.

\section{Conclusions}

Extensive experimental measurement of mixing times in two different size water models of a twin plug, slag covered industrial ladle were carried out as a function of gas flow rate, liquid depth, slag layer thickness and physical properties of the upper phase liquid. From the present work, the following major conclusions can be drawn:

(1) The physical properties of the upper phase liquid (e.g., density and viscosity combined) exert relatively small influence on bulk mixing time.

(2) Of all the characteristics of the upper phase liquid, the thickness $(\Delta L)$ of the latter influences mixing within the bulk of liquid most.

(3) In the inertial and gravitational force dominated flow regime (viz., $0.7<L / D<1.5, \varepsilon_{m} \sim 0.01 \mathrm{~W} / \mathrm{kg}, \quad v_{L}=$ $10^{-6} \mathrm{~m}^{2} / \mathrm{s}$ and $\left.0.01<\eta<0.13\right), 95 \%$ bulk mixing time in a ladle fitted with twin plugs (located diametrically opposite at mid bath radius positions) can be described via: $\tau_{\text {mix }, 95 \%, \text { slag }}=90 \eta^{0.3} Q^{-0.32} L^{-0.70} R^{2.0} v_{s}^{0.033}\left(\Delta \rho / \rho_{L}\right)^{-0.044}$.

(4) There exists strong correlation between mixing models for gas stirred ladles, with and without any upper phase liquid. Based on the present work as well as experimental observations reported in the literature, it is demonstrated that the correlation, $\tau_{\text {mix, } 95 \% \text {, Axisym-slag }} \approx$ $152 Q^{-0.33} L^{-1.0} R^{2.33}\left[\eta^{0.3} v_{s}^{0.03}\left(\Delta \rho / \rho_{L}\right)^{-0.04}\right]$ is adequate for estimating $95 \%$ mixing times in axisymmetrical, gas stirred ladle systems in the presence of an upper phase liquid.

(5) There is sufficient indication that commonly adopted gas flow rate scaling equation i.e., $Q_{\bmod } / Q_{f . s}=\lambda^{5 / 2}$ remains applicable in the presence of an upper phase liquid (slag) as well.

\section{Nomenclature}

$A_{\text {eye }}$ : Slag eye area

$C_{1}$ : Pre-exponent in the dimensionless mixing time correlation

$D: \quad$ Diameter of the vessel $(=2 R)(\mathrm{m})$

$g$ : Acceleration due to gravity $\left(\mathrm{m} / \mathrm{s}^{2}\right)$

$L: \quad$ Depth of liquid in the ladle (m)
$\Delta L: \quad$ Thickness of the upper phase liquid (m)

$Q$ : Gas flow rate (corrected to mean height and temperature of the liquid) $\left(\mathrm{m}^{3} / \mathrm{s}\right)$

$R: \quad$ Radius of the ladle $(\mathrm{m})$

$U_{P}:$ Plume rise velocity $(\mathrm{m} / \mathrm{s})$

$\mu$ : Viscosity of the upper phase liquid $(\mathrm{kg} /(\mathrm{m} \cdot \mathrm{s}))$

$\rho_{s}$ : Density of the upper phase liquid $\left(\mathrm{kg} / \mathrm{m}^{3}\right)$

$\rho_{L}$ : Density of the bulk liquid $\left(\mathrm{kg} / \mathrm{m}^{3}\right)$

$\Delta \rho$ : Density differential between upper phase and bulk liquid $\left(\mathrm{kg} / \mathrm{m}^{3}\right)$

$\sigma$ : Surface tension of the upper phase fluid $(\mathrm{N} / \mathrm{m})$

$v_{s}$ : Kinematic viscosity of the upper phase fluid $\left(\mathrm{m}^{2} / \mathrm{s}\right)$

$\tau_{\text {mix }}: 95 \%$ bulk mixing time (s)

$\varepsilon_{m}:$ Specific potential energy input rate $(\mathrm{W} / \mathrm{kg})$

$\eta$ : Dimensionless slag depth

\section{REFERENCES}

1) D. Mazumdar and R. I. L. Guthrie: ISIJ Int., 35 (1996), 1.

2) S. Joo and R. I. L.Guthrie: Metall. Trans., 23B (1992), 765.

3) M. Zhu, T. Inomoto, I. Sawada and T. C. Hsiao: ISIJ Int., 35 (1995), 472.

4) J. Mandal, D. Mazumdar, M. Madan and S. Patil: Metall. Mater. Trans. B, 36B (2005), 479.

5) S. H. Kim and R. J. Fruehan: Metall. Trans., 18B (1987), 381.

6) O. Haida and J. K. Brimacombe: Scaninject II, (1980), 20.

7) Q. Ying, L. Yun and L. Liu: Scaninject II, (1980), 22.

8) J. W. Han, S. H. Heo, D. H. Kam, B. D. You, J. J. Pak and H. K. Song: ISIJ Int., 41 (2001), 1165.

9) D. Mazumdar and J. W. Evans: ISIJ Int., 43 (2003), 2076.

10) D. Mazumdar and R. Guthrie: Metall. Mater. Trans. (in press).

11) Y. Sahai and R. I. L. Guthrie: Metall. Trans., 13B (1982), 193.

12) V. Sudhakar and D. Mazumdar: Metall. Mater. Trans., 27B (1996), 704.

13) D. Mazumdar and R. I. L. Guthrie: ISS Trans., 9 (1999), 89

14) D. Mazumdar, H. Nakajima and R. I. L. Guthrie: Metall. Trans., 19B (1988), 507

15) M. Iguchi, K. Takashahi, O. J. Ilegbussi, M. Sano and H. Kiuchi: ISIJ Int., 38 (1998), 1032.

16) V. Rajaraman: Computer Aided Numerical Methods, Prentice hall of India Limited, New Delhi, (2007).

17) D. Mazumdar and R. I. L. Guthrie: Metall. Trans., 17B (1986), 725.

18) S. P. Patil: M.Tech. Thesis, Indian Institute of Technology, Kanpur, (2005).

19) M. Peranandhanathan: M.Tech. Thesis, Indian Institute of Technology, Kanpur, (2010). 